Pacific Journal of Mathematics

SOME FUNCTION CLASSES RELATED TO THE CLASS O 


\title{
SOME FUNCTION CLASSES RELATED TO THE CLASS OF CONVEX FUNCTIONS
}

\author{
A. M. BRUCKNer AND E. Ostrow
}

1. Introduction. A real-valued function $f$ defined on the positive real line $[0, \infty)$ is said to be convex if for every $x \geqq 0, y \geqq 0$, and $\alpha, 0 \leqq \alpha \leqq 1, f$ satisfies the inequality

$$
f[\alpha x+(1-\alpha) y] \leqq \alpha f(x)+(1-\alpha) f(y) .
$$

Such functions are important in many parts of analysis and geometry and their properties have been studied in detail (see e.g. the expository article Beckenbach [1] which contains an extensive bibliography).

A related class of functions is the class of superadditive functions which satisfy the defining inequality

$$
f(x+y) \geqq f(x)+f(y) .
$$

These functions, more precisely their negatives which are subadditive, have been studied by Hille and Phillips [5] and R. A. Rosenbaum [7] among others.

In the paper we shall be concerned, in large part, with classes of functions that properly lie between these two classes and which are defined by inequalities which are weaker than (1) but stronger than (2). We obtain a strict hierarchy of classes and various characterizing properties of these classes and study a simple averaging operation that transforms each class into a smaller class.

2. Definitions and elementary properties of the classes. We shall restrict our attention generally to functions which are continuous, nonnegative, and for which $f(0)=0$ unless the contrary is explicitly stated. The requirement of being nonnegative simplifies many proofs which could be given without this assumption by considering the sum of $f$ with a suitably chosen linear function.

Definition 1. Let $f$ be defined on $[0, \infty)$. The average function $F$ of $f$ is the function defined for all $x>0$ by

$$
F(x)=\frac{1}{x} \int_{0}^{x} f(t) d t,
$$

Definition 2. The function $f$ is said to be starshaped if for each

Received January 10, 1962. 
$\alpha, 0 \leqq \alpha \leqq 1$, and all $x$

$$
f(\alpha x) \leqq \alpha f(x)
$$

It is easy to see that the set of points lying above the graph of a starshaped function is starshaped with respect to the origin in the usual sense. A function can, of course, be starshaped with respect to any other point on its graph, the definition of this phenomenon being made in an obvious way. The characterization of Lemma 3 below then applies mutatis mutandis. It is not hard to verify that a continuous function is convex if and only if it is starshaped with respect to a set of points dense in its graph.

Definition 3. The function $f$ is said to be convex on the average, starshaped on the average, or superadditive on the average if $F$ is respectively convex, starshaped, or superadditive.

In the sequel we shall use the abbreviation COA for convex on the average. We shall also use the following notation for derivatives:

$$
\underline{f}^{\prime}\left(x_{0}\right)=\lim _{h \rightarrow 0} \frac{f\left(x_{0}+h\right)-f\left(x_{0}\right)}{h}, f_{+}^{\prime}\left(x_{0}\right)=\lim _{h \rightarrow 0^{+}} \frac{f\left(x_{0}+h\right)-f\left(x_{0}\right)}{h},
$$

and

$$
f_{-}^{\prime}\left(x_{0}\right)=\lim _{h \rightarrow 0^{-}} \frac{f\left(x_{0}+h\right)-f\left(x_{0}\right)}{h} .
$$

Simple characterizations of the classes are recorded in the following series of lemmas.

Lemma 1. A continuous convex function $f$ is left and right differentiable at each point, the one-sided derivatives being increasing functions. Conversely, if any one of the Dini derivatives of a continuous function $f$ is increasing, the function is convex.

Proof. For a proof of the first part see Hardy, Littlewood, and Polya [4]. To prove the converse, let $D f$ denote an increasing Dini derivative of $f$ and let $G$ be an indefinite integral of $D f$. Then $G$ is convex. If $x_{0}$ is a point of continuity of $D f$, then both $f$ and $G$ are differentiable at $x_{0}$ and $D f\left(x_{0}\right)=G^{\prime}\left(x_{0}\right)=f^{\prime}\left(x_{0}\right)$. Since $D f$ is increasing, it is continuous except on at most a countable set of points. It follows (see Hobson [6]) that $f$ and $G$ differ by at most a constant. Thus $f$ is convex.

The proofs of the next three Lemmas are straightforward and will be omitted. 
Lemma 2. The function $f$ is COA if and only if $\underline{f}^{\prime} \geqq 2 F^{\prime}$.

LEMMA 3. The function $f$ is starshaped if and only if either one the two following conditions is satisfied:

(i) $f(x) / x$ is increasing,

(ii) $\underline{f}^{\prime}(x) \geqq f(x) / x$ for all $x$.

LEMma 4. The function $f$ is starshaped on the average if and only if $f \geqq 2 F$.

The inequality $f \geqq 2 F$ has the following simple geometric interpretation: Since

$$
x F(x)=\int_{0}^{x} f(t) d t \leqq \frac{x}{2} f(x),
$$

the area under the graph of $f$ is at each point dominated by the area of the triangle with vertices $(0,0),(x, 0)$ and $(x, f(x))$.

The inequality $f\left(x_{0}\right) \geqq 2 F\left(x_{0}\right)$ can be cast in the form

$$
\frac{F\left(x_{0}\right)}{x_{0}} \leqq \frac{1}{2} \frac{f\left(x_{0}\right)}{x_{0}}
$$

Since $F(x) / x$ is increasing, we actually obtain the slightly more general result,

$$
\frac{F(a)}{a} \leqq \frac{F\left(x_{0}\right)}{x_{0}} \leqq \frac{1}{2} \frac{f\left(x_{0}\right)}{x_{0}}
$$

for all $a \leqq x_{0}$. This means geometrically that for $a<x_{0}$, the area of the triangle cut off from the above mentioned triangle by the line $x=a$ is no smaller than the area under the graph of $f$ from 0 to $a$.

LEMma 5. If $f$ is respectively convex, convex on the average, starshaped, or superadditive, then $f$ is a nondecreasing function.

Proof. We have restricted ourselves to nonnegative functions for which $f(0)=0$. If $f$ is superadditive, then $f(y)=f[x+(y-x)]$

$$
\geqq f(x)+f(y-x) \geqq f(x) \text { for } y \geqq x \text {. }
$$

As we show in Theorem 5, $f$ satisfying any of the other conditions implies that $f$ is superadditive.

If $f$ is merely starshaped on the average, it is clear from the geometric interpretation of $f \geqq 2 F$ that $f$ need not be increasing.

Since $f$ is an increasing function provided $f$ belongs to one of the function classes of Lemma $5, f$ has a finite derivative almost everywhere. For all these classes, $F$ has a continuous derivative for $x>0$ 
since $x F^{\prime}(x)=f(x)-F(x)$. We consider the behavior of $F^{\prime}$ at the origin in Theorem 7 below.

We now investigate various operations under which our function classes are closed. We have first of all

THeOREM 1. Let $f$ and $g$ be respectively convex, COA, starshaped, starshaped on the average, superadditive, superadditive on the average; then for $a \geqq 0, b \geqq 0, a f+b g$ belongs to the same class.

The proof involves a trivial computation.

The next two theorems consider the behavior of our classes under the operation of pointwise limits.

THEOREM 2. Let $\left\{f_{n}\right\}$ be a sequence of convex, starshaped, or superadditive functions converging pointwise to a limit function $f$. Then $f$ is respectively convex, starshaped, or superadditive. Moreover, the average functions $F_{n}$ converge to the average function $F$.

Proof. It is clear that the defining inequalities of these classes are preserved in the limit. The proof of the second statement parallels the proof of the corresponding part of Theorem 3 .

THEOREM 3. Let $\left\{f_{n}\right\}$ be a sequence of COA functions converging pointwise to a continuous limit $f$. The limit function is then COA and the average functions $F_{n}$ converge to the average function $F$.

Proof. Let $b>0$. The sequence $\left\{f_{n}\right\}$ is uniformly bounded on $[0, b]$ by $\sup \left\{f_{n}(b)\right\}=M . \quad M$ is finite for $f_{n}(b) \rightarrow f(b)$ and $M$ is a uniform bound because each $f_{n}$ is an increasing function. By the Lebesgue bounded convergence theorem,

$$
\frac{1}{x} \int_{0}^{x} f_{n}(t) d t \rightarrow \frac{1}{x} \int_{0}^{x} f(t) d t
$$

for each $x \in[0, b]$, that is $F_{n}(x) \rightarrow F(x)$. Since $b$ was arbitrary, this last relation holds for all $x$. The convexity of $F$ follows from the convexity of $F_{n}$.

In general, however, it is not true that the limit of the average functions is equal to the average of the limit function. If $f_{n} \rightarrow f$ and the averages $F_{n} \rightarrow G$, an easy calculation shows that $F \leqq G$. For functions which are starshaped on the average, we do have the following theorem.

THEOREM 4. If $\left\{f_{n}\right\}$ is starshaped on the average and $f_{n} \rightarrow f$, then $f$ is starshaped on the average. 
Proof. For each $x>0$, let $T_{n}^{x}$ and $T^{x}$ be the linear functions determined by the origin and the points $\left(x, f_{n}(x)\right)$ and $(x, f(x))$. Since $f_{n} \rightarrow f, T_{n}^{x} \rightarrow T^{x}$. Moreover, the inequality $2 F_{n} \leqq f_{n}$ is equivalent to

$$
\int_{0}^{x} f_{n}(t) d t \leqq \int_{0}^{x} T_{n}^{x}(t) d t
$$

by Fatou's theorem,

$$
\int_{0}^{x} f(t) d t \leqq \lim _{n \rightarrow \infty} \int_{0}^{x} f_{n}(t) d t \leqq \lim _{n \rightarrow \infty} \int_{0}^{x} T_{n}^{x}(t) d t=\int_{0}^{x} T^{x}(t) d t .
$$

Thus,

$$
\frac{1}{x} \int_{0}^{x} f(t) d t \leqq \frac{1}{x} \int_{0}^{x} T^{x}(t) d t=\frac{1}{2} f(x),
$$

i.e.

$$
F(x) \leqq \frac{1}{2} f(x)
$$

so $f$ is starshaped on the average.

3. The hierarchy. We now consider the inclusion relationships among the six classes.

THEOREM 5. Let $f$ be a nonnegative continuous function which vanishes at the origin.

Consider the following six conditions on $f$ :

(i) $f$ is convex,

(ii) $f$ is COA,

(iii) $f$ is starshaped,

(iv) $f$ is superadditive,

(v) $f$ is starshaped on the average,

(vi) $f$ is superadditive on the average.

Then the following chain of implications is valid but none of the reverse implications holds: (i) $\rightarrow$ (ii) $\rightarrow$ (iii) $\rightarrow$ (iv) $\rightarrow$ (v) $\rightarrow$ (vi).

Proof. (i) $\rightarrow$ (ii). This will be a consequence of Theorem 10 . (ii) $\rightarrow$ (iii).

$$
\frac{f(x)}{x}=F^{\prime}(x)+\frac{F(x)}{x} .
$$

Since $F$ is convex, both $F^{\prime}$ and $F(x) / x$ are increasing. Thus $f(x) / x$ is increasing. It follows from Lemma 3 , condition (i), that $f$ is starshaped.

(iii) $\rightarrow$ (iv). For $x>0$ and $y>0$, we have 


$$
\frac{f(x)}{x} \leqq \frac{f(x+y)}{x+y}
$$

and

$$
\frac{f(y)}{y} \leqq \frac{f(x+y)}{x+y}
$$

These inequalities are equivalent to

$$
(x+y) f(x) \leqq x f(x+y)
$$

and

$$
(x+y) f(y) \leqq y f(x+y)
$$

which on addition yield $f(x)+f(y) \leqq f(x+y)$.

(iv) $\rightarrow$ (v). We first consider the case in which $f$ is a polygonal superadditive function. The general case then follows by a limit argument.

Let $x>0$ and let $f$ be polygonal of $n$ segments with vertices over the equidistantly spaced points $0, v, 2 v, \cdots, n v=x$. Let $T$ be the linear function determined by the origin and the point $(x, f(x))$, i.e. $T(t)=(f(x) / x) t$ for all $t$. Furthermore, let $q(t)=f(t)-T(t)$. The function $q$ is polygonal and superadditive, having its vertices over the same points as $f$, and $q(0)=q(x)=0$. We will show that $\int_{0}^{x} q(t) d t \leqq 0$ which suffices for $F$ to be starshaped. Using the linearity of $f$ on the intervals $[k v,(k+1) v]$, we obtain

$$
\begin{aligned}
\int_{0}^{x} q(t) d t & =v \sum_{k=1}^{n-1} q(k v) \\
& = \begin{cases}\left.v \sum_{k=1}^{(n-1) / 2}[q(k v)+q(n-k) v)\right] & \text { if } n \text { is odd, } \\
v q((n / 2) v)+v \sum_{k=1}^{n / 2-1}[q(k v)+q((n-k) v)] & \text { if } n \text { is even . }\end{cases}
\end{aligned}
$$

Now $q(k v)+q((n-k) v) \leqq q(n v)=q(x)=0$ for $q$ is superadditive. In either case $\int_{0}^{x} q(t) d t \leqq 0$.

In the general case let $\left\{p_{n}\right\}$ be a sequence of polygonal functions over equidistantly spaced points such that $p_{n} \rightarrow f$. Let $T$ be the linear function defined as above related to $f$. Since $\left\{p_{n}\right\}$ is superadditive for each $n$ (see Bruckner [2, THEOREM 8] and $p_{n}(x) \leqq f(b)$ for all $n$ and all $x \leqq b$, where $b$ is arbitrary, it follows for each $x$ that

$$
\int_{0}^{x} p_{n}(t) d t \rightarrow \int_{0}^{x} f(t) d t
$$

Since 


$$
\int_{0}^{x} p_{n}(t) d t \leqq \int_{0}^{x} T(t) d t
$$

the limit result

$$
\int_{0}^{x} f(t) d t \leqq \int_{0}^{x} T(t) d t
$$

follows.

(v) $\rightarrow$ (vi). This is just the case (iii) $\rightarrow$ (iv) for $F$.

That none of the reverse implications hold is shown by the following examples:

(ii) $\rightarrow$ (i): $f(x)=x^{2}-x^{3}$ is COA on $[0,4 / 9]$ but convex only on $[0,1 / 3]$.

(iii) $\rightarrow$ (ii):

$$
f(x)= \begin{cases}x^{2} & 0 \leqq x \leqq 1 \\ x & 1<x\end{cases}
$$

is starshaped on $[0, \infty)$ but COA only on $[0,1]$.

(iv) $\rightarrow$ (iii): $f(x)=n+(x-n)^{2}$ for $n \leqq x<n+1,(n=0,1,2, \cdots)$ is superadditive on $[0, \infty)$ but starshaped only on $[0,1]$.

(v) $\rightarrow$ (iv): Let $f$ be any function that is starshaped on the average without being increasing.

(vi) $\rightarrow$ (v): Let $F$ be any superadditive function which is not starshaped such that $F^{\prime}$ is continuous. Then $x F(x)$ has a continuous derivative $f(x)$ and $F$ is the average function of $f$.

4. Behavior for large and small $x$. Our first theorem in this section shows that superadditive functions are differentiable at the origin. Actually, a weaker hypothesis suffices to give this result.

THEOREM 6. Let $f$ be a continuous nonnegative function on $[0, c]$, $f(0)=0$, such that $f((1 / n) x) \leqq(1 / n) f(x)$ for all $n=1,2,3, \cdots$, and for all $x \in[0, c]$. Then $f$ is differentiable at $x=0$.

Proof. The hypothesis $f((1 / n) x) \leqq(1 / n) f(x)$ implies that

$$
\varlimsup_{x \rightarrow 0} \frac{f(x)}{x}<\infty \text {. }
$$

Suppose $f$ is not differentiable at the origin. Then there exists an $\varepsilon>0$ such that $\bar{f}^{\prime}(0)-f^{\prime}(0)=3 \varepsilon$. Choose $x_{0}$ so that $f\left(x_{0}\right)<\left(f^{\prime}(0)+\varepsilon\right) x_{0}$ and let $\left\{y_{k}\right\}$ be a sequence such that $y_{k} \rightarrow 0$ and $f\left(y_{k}\right)>\left(\bar{f}^{\prime}(0)-\varepsilon\right) y_{k}$ $(k=1,2,3, \cdots)$. Since $f$ is continuous at $x_{0}$, there is a $\delta>0$ such that if $\left|x-x_{0}\right|<\delta$, then $f(x)<\left(\underline{f}^{\prime}(0)+\varepsilon\right) x$. Let $y^{*}$ be a member of the sequence $\left\{y_{k}\right\}$ such that $y^{*}<\bar{\delta}$. There is then an integer $N$ such 
that

$$
\left|N y^{*}-x_{0}\right|<\delta ; \text { hence } f\left(N y^{*}\right)<\left(\underline{f}^{\prime}(0)+\varepsilon\right) N y^{*} .
$$

However

$$
f\left(y^{*}\right) \leqq \frac{1}{N} f\left(N y^{*}\right)<\left(\underline{f}^{\prime}(0)+\varepsilon\right) y^{*}<\left(\bar{f}^{\prime}(0)-\varepsilon\right) y^{*}
$$

which contradicts the fact $y^{*}$ is a member of the sequence $\left\{y_{k}\right\}$. Thus $f$ is differentiable at the origin.

COROLlaRY. If $f$ is superadditive, in particular if $f$ is starshaped, COA, or convex, then $f^{\prime}(0)$ exists.

THEOREM 7. Let $f$ be superadditive on the average, and let $F$ be its average function. If $f^{\prime}(0)$ exists, then $F^{\prime}$ is continuous at $x=0$ and $f^{\prime}(0)=2 F^{\prime}(0)$.

Proof.

$$
F^{\prime}(x)=\frac{f(x)}{x}-\frac{F(x)}{x}
$$

The right member of this equality approaches $f^{\prime}(0)-F^{\prime}(0)$ for $F^{\prime}(0)$ exists by Theorem 6 ; hence $\lim _{x \rightarrow 0} F^{\prime}(x)$ exists, and because $F^{\prime}$ is a derivative, this limit must be $F^{\prime}(0)$. Thus, $F^{\prime}$ is continuous at $x=0$ and $2 F^{\prime}(0)=f^{\prime}(0)$.

Theorem 7 indicates that $2 F(x) / x$ is approximately the same as $f(x) / x$ for $x$ near 0 , provided $f$ behaves sufficiently well near the origin. The next theorem shows that under suitable hypotheses the same behavior holds for large $x$.

THEOREM 8. Let $f$ be increasing and starshaped on the average and let $F$ be its average function. Then $\lim _{x \rightarrow \infty} f(x) / x$ exists and is equal to $2 \lim _{x \rightarrow \infty} F(x) / x$.

Proof. Since $F$ is starshaped, the $\lim _{x \rightarrow \infty} F(x) / x$ exists.

Let $\alpha$ be such that $0<\alpha<1$ and let $M=\varlimsup_{x \rightarrow \infty}(f(x) / x)$. Then

$$
\begin{aligned}
\frac{F(x)}{x} & =\frac{1}{x^{2}} \int_{0}^{x} f(t) d t \\
& =\frac{1}{x^{2}} \int_{0}^{\alpha x} f(t) d t+\frac{1}{x^{2}} \int_{\alpha x}^{x} f(t) d t
\end{aligned}
$$




$$
\geqq \frac{\alpha F(\alpha x)}{x}+\frac{1-\alpha}{x} f(\alpha x) \text {. }
$$

It follows that

$$
\lim _{x \rightarrow \infty} \frac{F(x)}{x} \geqq \alpha^{2} \lim _{x \rightarrow \infty} \frac{F(x)}{x}+\alpha(1-\alpha) M .
$$

This last inequality holds for all $\alpha, 0<\alpha<1$ so

$$
\lim _{x \rightarrow \infty} \frac{F(x)}{x} \geqq \sup _{0<\alpha<1} \frac{\alpha M}{1+\alpha}=\frac{M}{2} .
$$

On the other hand, since $F$ is starshaped, $f(x) \geqq 2 F(x)$ for all $x$ so that

$$
\lim _{x \rightarrow \infty} \frac{F(x)}{x} \leqq \frac{1}{2} \lim _{x \rightarrow \infty} \frac{f(x)}{x} .
$$

It follows that $\lim _{x \rightarrow \infty}(f(x) / x)$ exists and equals $2 \lim _{x \rightarrow \infty}(F(x) / x)$.

COROLLARY. Let $f$ be increasing and starshaped on the average with average function $F$. Then the three functions $f(x) / x, F^{\prime}(x)$, and $F(x) / x$ simultaneously are bounded or unbounded.

Proof. This follows directly from the identity

$$
\frac{f(x)}{x}=F^{\prime}(x)+\frac{F(x)}{x}
$$

and the preceding theorem.

5. Minimal extensions. We suppose in this section that $f$ is defined initially on an interval $[0, c]$. We shall consider in this section the problem of extending $f$ in a minimal way to $[0, \infty)$ while staying within the same class. We start with

DeFINITION 4. Let $f$ be convex (COA, starshaped, superadditive) on $[0, c]$. Suppose $\hat{f}$ is a function defined on $[0, \infty)$ with the following properties:

(i) $\hat{f}=f$ on $[0, c]$,

(ii) $\hat{f}$ is convex (COA, starshaped, superadditive) on $[0, \infty)$,

(iii) if $g$ is any function on $[0, \infty)$ satisfying (i) and (ii), then $g(x) \geqq \widehat{f}(x)$ for all $x$;

then $\hat{f}$ is said to be the minimal convex (COA, starshaped, superadditive) extension of $f$.

We restrict our definition to functions which are at least superad- 
ditive for minimal extensions of functions in the larger two classes are not, in general, continuous.

It is well known that if $f$ is convex on $[0, c]$, there exists a convex extension of $f$ to $[0, \infty)$ precisely when $f_{-}^{\prime}(c)<\infty$. In this case, the minimal convex extension of $f$ is linear on $[c, \infty)$ with slope $f_{-}^{\prime}(c)$. When $f$ is starshaped, it is clear that the minimal starshaped extension of $f$ to $[0, \infty)$ is the linear function with slope $f(c) / c$. For superadditive functions the situation is much more complicated and has been studied in detail in Bruckner [2], where it is shown that the minimal extension does exist and, roughly speaking, behaves about as well as $f$.

The following theorem states the corresponding result for functions that are $\mathrm{COA}$ on $[0, c]$.

Theorem 9. Suppose $f$ is COA on $[0, c]$ with average function $F$. Define $\hat{f}$ by the equations

$$
\hat{f}(x)=\left\{\begin{array}{lr}
f(x) & 0 \leqq x \leqq c \\
2 F_{-}^{\prime}(c) x+f(c)-2 F_{-}^{\prime}(c) x & x>c ;
\end{array}\right.
$$

then $\hat{f}$ is the minimal COA extension of $f$ to $[0, \infty)$. If $\hat{F}$ is the average function of $\hat{f}$, then $\hat{F}$ is the minimal convex extension of $F$ to $[0, \infty)$.

Proof. For $x \geqq c$, we have

$$
\hat{F}(x)=\frac{1}{x} \int_{0}^{c} f(t) d t+\frac{1}{x} \int_{c}^{x}\left[2 F_{-}^{\prime}(c) t+f^{\prime}(c)-2 F_{-}^{\prime}(c) c\right] d t .
$$

It is easy to check that $\hat{F}(c)=F(c)$ and that for $x>c, \hat{F}^{\prime \prime}(x)=0$ and $\hat{F}^{\prime}(x)=\hat{F}_{-}^{\prime}(c)$ so that $\hat{F}$ is the minimal convex extension of $F$ to $[0, \infty)$. Thus $\hat{f}$ is a COA extension of $f$ to $[0, \infty)$. Let now $g$, with average function $G$, be any COA extension of $f$ to $[0, \infty)$ and let $x>c$. Since $G$ is convex, $G^{\prime}$ is increasing so

$$
G^{\prime}(x) \geqq G_{-}^{\prime}(c)=F_{-}^{\prime}(c)=\hat{F}^{\prime}(x) .
$$

Thus

$$
\underline{g}^{\prime}(x) \geqq 2 G^{\prime}(x) \geqq 2 \hat{F}^{\prime}(x)=\hat{f}^{\prime}(x) .
$$

Since $\hat{f}$ and $g$ agree at $c$ and $g^{\prime} \geqq \hat{f}^{\prime}, g(x) \geqq \hat{f}(x)$ so $\hat{f}$ is indeed the minimal COA extension of $f$.

If a function is convex on $[0, c]$, then it has extensions of each of the four types mentioned above. It is interesting to compare these various extensions. As an example, consider the function $f(x)=x^{2}$ on $[0,1]$. Its minimal convex extension is linear with slope 2 , the minimal COA extension is linear with slope $4 / 3$, and the minimal starshaped 
extension is linear with slope 1 . In contrast, the minimal superadditive extension is not linear. It is given by the function $\hat{f}(x)=n+(x-n)^{2}$ for $n \leqq x<n+1, n=1,2,3, \cdots$ (see Bruckner [2], $\mathrm{p}$ 1155).

6. Tests for convexity on the average. In this section we shall consider conditions that are necessary and/or sufficient that a function be COA. Similar tests concerning superadditive functions are found in Bruckner [3]. We begin with the following lemma.

Lemma 6. Let $f_{c}$ be the function such that

$$
f_{c}(x)=\left\{\begin{array}{lr}
0 & 0 \leqq x \leqq c \\
f(x-c) & x>c .
\end{array}\right.
$$

If $f$ is $\mathrm{COA}$, then $f_{c}$ is $\mathrm{COA}$.

Proof. Let $F_{c}$ be the average function of $f_{c}$. We shall show that $\underline{f}_{c}^{\prime}(x) \geqq 2 F_{c}^{\prime}(x), x \geqq c$. Since $\underline{f}_{c}^{\prime}(x)=\underline{f}^{\prime}(x-c)$ for $x \geqq c$, it suffices to show that $f^{\prime}(x-c) \geqq 2 F_{c}^{\prime}(x)$. This last inequality will be a consequence of the inequality $F^{\prime}(x-c) \geqq F_{c}^{\prime}(x)$.

Defining

$$
A(x)=\int_{0}^{x-c} f(t) d t
$$

we have that

$$
F(x-c)=\frac{1}{x-c} \int_{0}^{x-c} f(t) d t=\frac{A(x)}{x-c}
$$

and

$$
\begin{aligned}
F_{c}(x) & =\frac{1}{x} \int_{0}^{x} f_{c}(t) d t=\frac{1}{x} \int_{c}^{x} f(t-c) d t \\
& =\frac{1}{x} \int_{0}^{x-c} f(t) d t=\frac{A(x)}{x} .
\end{aligned}
$$

It thus suffices to show that

$$
\left[A(x)(x-c)^{-1}\right]^{\prime} \geqq\left[A(x) x^{-1}\right]^{\prime},
$$

the " " denoting differentiation with respect to $x$. This last inequality is equivalent to

$$
A^{\prime}(x) \geqq \frac{2 x-c}{x(x-c)} A(x),
$$

which is, on replacing $A(x)$ by $\int_{0}^{x-c} f(t) d t$ and simplifying, equivalent to 
the relation

$$
f(x-c) \geqq \frac{2 x-c}{x} F(x-c) .
$$

Since $f$ is starshaped, $f$ is superadditive; hence $f$ is starshaped on the average. Thus, by Lemma 4,

$$
f(x-c) \geqq 2 F(x-c) \geqq \frac{2 x-c}{x} F(x-c)
$$

which proves the lemma.

Definition 5. Let $f$ be defined on $[0, a]$. The functions $f_{1}, f_{2}, \cdots$, $f_{n}$ defined on $\left[0, a_{1}\right],\left[0, a_{2}\right], \cdots,\left[0, a_{n}\right]$ respectively form a decomposition of $f$ provided

(i) $f_{i}(0)=0$

$$
i=1, \cdots, n
$$

(ii) $a_{1}+a_{2}+\cdots+a_{n}=a$ and $a_{i}>0$ for $i=1, \cdots, n$

(iii) $f(x)=\left\{\begin{array}{lr}f_{1}(x) & 0 \leqq x \leqq a_{1} \\ f_{2}\left(x-a_{1}\right)+f_{1}\left(a_{1}\right) & a_{1}<x \leqq a_{1}+a_{2} \\ \cdots & \\ f_{n}\left(x-a_{1}-a_{2}-\cdots-a_{n-1}\right)+f_{1}\left(a_{1}\right)+\cdots+f_{n-1}\left(a_{n-1}\right)\end{array}\right.$

In this case we write $f=f_{1} \wedge f_{2} \wedge \cdots \wedge f_{r}$.

$$
a-a_{n}<x \leqq a .
$$

THEOREM 10. Let $f_{1}$ and $f_{2}$ be COA on $\left[0, a_{1}\right]$ and $\left[0, a_{2}\right]$ respectively and let $f=f_{1} \wedge f_{2}$ on $\left[0, a_{1}+a_{2}\right]$. Let $\hat{f}_{1}$ be the minimal COA extension of $f_{1}$. A necessary and sufficient condition that $f$ be COA is that $f \geqq \hat{f}_{1}$ on $\left[0, a_{1}+a_{2}\right]$.

Proof. The necessity is obvious. As to the sufficiency let $\hat{F}_{1}$ be the average function of $\hat{f}_{1}$. For $x \in\left[0, a_{1}+a_{2}\right]$, write

$$
F(x)=\hat{F}_{1}(x)+\left[F(x)-\hat{F}_{1}(x)\right]=\hat{F}_{1}(x)+\frac{1}{x} \int_{0}^{x}\left[f(t)-\hat{f}_{1}(t)\right] d t .
$$

Consider $g(t)=f(t)-\hat{f}_{1}(t) . \quad g(t)=0$ on $\left[0, a_{1}\right]$ so there is an $h$ defined on $\left[0, a_{2}\right]$ such that $g(t)=h_{a_{1}}(t)$ for $t \in\left[0, a_{1}+a_{2}\right]$. On $\left[a_{1}, a_{1}+a_{2}\right]$, $-\hat{f}_{1}$ is linear. Since $f_{2}$ is COA on $\left[0, a_{2}\right], h$ is COA on $\left[0, a_{2}\right]$ being the sum of COA functions. It follows from Lemma 6 that $g$ is COA on $\left[0, a_{1}+a_{2}\right]$. Its average function is therefore convex and so $F$ is the sum of convex functions; hence convex.

THEOREM 11. Let $f_{1}, \cdots, f_{n}$ be COA on $\left[0, a_{1}\right], \cdots,\left[0, a_{n}\right]$ respectively and let $f=f_{1} \wedge f_{2} \wedge \cdots \wedge f_{n}$. Furthermore let $\hat{f}_{k}$ be the mimimal COA extension of $f_{k},(k=1, \cdots, n)$. Then $f$ is COA on $\left[0, a_{1}+\cdots+a_{n}\right]$ 
if $f_{k} \wedge f_{k+1} \wedge \cdots \wedge f_{n} \geqq \hat{f}_{k}$ for each $k=1,2, \cdots, n$.

Proof. The proof is an induction argument using the sufficiency part of Theorem 10.

We now return to the proof of the first part of Theorem 5, namely the proof of the statement: if $f$ is convex, then $f$ is COA.

Proof. Let us assume first that $f$ is a polygonal function on $[0, c]$. If $f$ has only one segment, then $f$ is linear so the theorem is trivially true.

Supposing, by induction, that the theorem holds for polygonal functions with $n$ segments, let $f$ be polygonal with $(n+1)$ segments. Let $f_{n}$ be the polygonal function which agrees with $f$ on the first $n$ segments of $f$ and let $\hat{f}_{n}$ be the minimal convex extension of $f_{n}$ to $[0, c]$. Thus $\hat{f}_{n}$ is convex and polygonal with $n$ segments and so is COA. On the last segment $f$ is linear and $f \geqq \hat{f}_{n}$. By Theorem 10 , $f$ is $\mathrm{COA}$ on $[0, c]$.

The general situation follows immediately by Theorem 3 . Let $\left\{p_{n}\right\}$ be a sequence of convex polygonal functions approximating $f$. The $\left\{p_{n}\right\}$ are thus COA and so their limit function $f$ is COA on $[0, c]$. Since $c$ is arbitrary, this concludes the proof.

\section{BIBLIOGRAPHY}

1. E. F. Beckenbach, Convex functions, Bull. Amer. Math. Soc., 54 (1948), 439-460.

2. A. M. Bruckner, Minimal superadditive extensions of superadditive functions, Pacific J. Math., 10 (1960), 1155-1162.

3. - Tests for the superadditivity of functions, Proc. Amer. Math Soc., 13 (1962), $126-130$.

4. G. H. Hardy, J. E. Littlewood, and G. Polya, Inequalities, 2nd Edition, Cambridge, 1952, p. 91.

5. E. Hille and R. S. Phillips, Functional Analysis and semi-groups, Amer. Math. Soc. Colloquium Publications, vol. XXXI, Ch. 7.

6. E. H. Hobson, Theory of functions of a real variable, vol. 1, 3rd edition, Cambridge 1927, p. 364.

7. R. A. Rosenbaum, Subadditive functions, Duke Math. J., 17 (1950), 227-247.

UNIVERSITY OF CALIFORNIA,

SANTA BARBARA 



\section{PACIFIC JOURNAL OF MATHEMATICS}

\section{EDITORS}

\author{
Ralph S. Phillips \\ Stanford University \\ Stanford, California \\ M. G. Arsove \\ University of Washington \\ Seattle 5 , Washington
}

\author{
A. L. Whiteman \\ University of Southern California \\ Los Angeles 7, California \\ Lowell J. Paige \\ University of California \\ Los Angeles 24, California
}
E. F. BECKENBACH
D. DERRY
ASSOCIATE EDITORS
T. M. CHERRY
M. OHTSUKA
H. L. ROYDEN
E. G. STRAUS
E. SPANIER
F. WOLF

\section{SUPPORTING INSTITUTIONS}

\author{
UNIVERSITY OF BRITISH COLUMBIA \\ CALIFORNIA INSTITUTE OF TECHNOLOGY \\ UNIVERSITY OF CALIFORNIA \\ MONTANA STATE UNIVERSITY \\ UNIVERSITY OF NEVADA \\ NEW MEXICO STATE UNIVERSITY \\ OREGON STATE UNIVERSITY \\ UNIVERSITY OF OREGON \\ OSAKA UNIVERSITY \\ UNIVERSITY OF SOUTHERN CALIFORNIA
}

\author{
STANFORD UNIVERSITY \\ UNIVERSITY OF TOKYO \\ UNIVERSITY OF UTAH \\ WASHINGTON STATE UNIVERSITY \\ UNIVERSITY OF WASHINGTON \\ AMERICAN MATHEMATICAL SOCIETY \\ CALIFORNIA RESEARCH CORPORATION \\ SPACE TECHNOLOGY LABORATORIES \\ NAVAL ORDNANCE TEST STATION
}

Mathematical papers intended for publication in the Pacific Journal of Mathematıcs should be typewritten (double spaced), and the author should keep a complete copy. Manuscripts may be sent to any one of the four editors. All other communications to the editors should be addressed to the managing editor, L. J. Paige at the University of California, Los Angeles 24, California.

50 reprints per author of each article are furnished free of charge; additional copies may be obtained at cost in multiples of 50 .

The Pacific Journal of Mathematics is published quarterly, in March, June, September, and December. Effective with Volume 13 the price per volume (4 numbers) is $\$ 18.00$; single issues, $\$ 5.00$. Special price for current issues to individual faculty members of supporting institutions and to individual members of the American Mathematical Society: $\$ 8.00$ per volume; single issues $\$ 2.50$. Back numbers are available.

Subscriptions, orders for back numbers, and changes of address should be sent to Pacific Journal of Mathematics, 103 Highland Boulevard, Berkeley 8, California.

Printed at Kokusai Bunken Insatsusha (International Academic Printing Co., Ltd.), No. 6, 2-chome, Fujimi-cho, Chiyoda-ku, Tokyo, Japan.

PUBLISHED BY PACIFIC JOURNAL OF MATHEMATICS, A NON-PROFIT CORPORATION

The Supporting Institutions listed above contribute to the cost of publication of this Journal, but they are not owners or publishers and have no responsibility for its content or policies. 


\section{Pacific Journal of Mathematics}

\section{Vol. 12 , No. 4 \\ April, 1962}

Tsuyoshi Andô, On fundamental properties of a Banach space with a cone ..... . 1163

Sterling K. Berberian, A note on hyponormal operators ................ 1171

Errett Albert Bishop, Analytic functions with values in a Frechet space . . . . . . . 1177

(Sherman) Elwood Bohn, Equicontinuity of solutions of a quasi-linear equation ............................................ 1193

Andrew Michael Bruckner and E. Ostrow, Some function classes related to the class of convex functions . . . . . . . . . . . . . . . . . . . . . . . . 1203

J. H. Curtiss, Limits and bounds for divided differences on a Jordan curve in the complex domain . . ................................. 1217

P. H. Doyle, III and John Gilbert Hocking, Dimensional invertibility . . . . . . . . 1235

David G. Feingold and Richard Steven Varga, Block diagonally dominant matrices and generalizations of the Gerschgorin circle theorem ................. 1241

Leonard Dubois Fountain and Lloyd Kenneth Jackson, A generalized solution of the boundary value problem for $y^{\prime \prime}=f\left(x, y, y^{\prime}\right) \ldots \ldots \ldots \ldots \ldots \ldots \ldots \ldots \ldots$

Robert William Gilmer, Jr., Rings in which semi-primary ideals are primary. . . . . 1273

Ruth Goodman, K-polar polynomials .......................... 1277

Israel Halperin and Maria Wonenburger, On the additivity of lattice completeness ........................................... 1289

Robert Winship Heath, Arc-wise connectedness in semi-metric spaces . . . . . . . . 1301

Isidore Heller and Alan Jerome Hoffman, On unimodular matrices . . . . . . . . . . . 1321

Robert G. Heyneman, Duality in general ergodic theory . . . . . . . . . . . . . . . 1329

Charles Ray Hobby, Abelian subgroups of p-groups . . . . . . . . . . . . . . . 1343

Kenneth Myron Hoffman and Hugo Rossi, The minimum boundary for an analytic

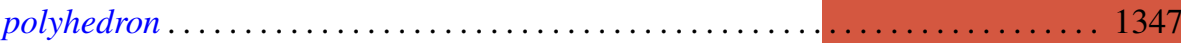

Adam Koranyi, The Bergman kernel function for tubes over convex cones ........ 1355

Pesi Rustom Masani and Jack Max Robertson, The time-domain analysis of a continuous parameter weakly stationary stochastic proces.

William Schumacher Massey, Non-existence of almost-complex structures on

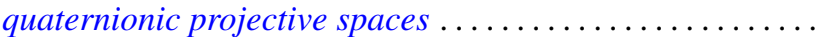

Deane Montgomery and Chung-Tao Yang, A theorem on the action of $\mathrm{SO}(3) \ldots . .1385$

Ronald John Nunke, A note on Abelian group extensions . . . . . . . . . . . . . 1401

Carl Mark Pearcy, A complete set of unitary invariants for operators generating finite $W^{*}$-algebras of type $I$

Edward C. Posner, Integral closure of rings of solutions of linear differential equations.

Duane Sather, Asymptotics. III. Stationary phase for two parameters with an application to Bessel functions.

J. Śladkowska, Bounds of analytic functions of two complex variables in domains

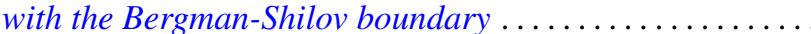

Joseph Gail Stampfli, Hyponormal operators .

George Gustave Weill, Some extremal properties of linear combinations of kernels

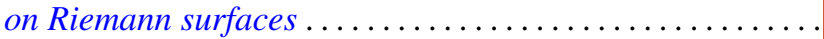

